\title{
Misusing our talent? Overeducation, overskilling and skill underutilisation among Spanish $\mathrm{PhD}$ graduates
}

\author{
Antonio Di Paolo \\ AQR-IREA, Universitat de Barcelona, Spain
}

Ferran Mañé

Universitat Rovira i Virgili, Reus, Spain

Corresponding author: Ferran Mañé, Department of Economics, Universitat Rovira i Virgili, Avinguda de la Universitat, 1, 43202 Reus, Spain. Email: ferran.mane@urv.cat.

\begin{abstract}
The 'knowledge economy' is said to depend increasingly on capacities for innovation, knowledgegeneration and complex problem-solving - capacities attributed to university graduates with research degrees. To what extent, however, is the labor market absorbing and fully utilizing these capabilities? Drawing on data from a recent cohort of $\mathrm{PhD}$ graduates, we examine the correlates and consequences of qualification and skills mismatch. We show that job characteristics such as economic sector and main work activity play a fundamental and direct role in explaining the phenomenon of mismatch, experienced as overeducation and overskilling. Academic attributes operate only indirectly in explaining this mismatch, since their effect loses importance once we control for job-related characteristics. We detected a significant earnings penalty for those who are both overeducated and overskilled. Being mismatched reduces satisfaction with the job as a whole and with non-monetary aspects of the job, especially for those whose skills are underutilized. Overall, the problem of mismatch among $\mathrm{PhD}$ graduates is closely related to the demand-side constraints of the labor market. Increasing the number of adequate jobs and broadening the job skills that $\mathrm{PhD}$ students acquire during training should be explored as possible responses.
\end{abstract}

Keywords:

Doctors, earnings, graduate attributes, graduate employment, job satisfaction, overskilling, overeducation, skill underutilisation

JEL classifications: I20, J24, J28, J31

\section{Introduction}

In recent decades we have witnessed the emergence and consolidation of the so-called knowledge economy, in which economic success does not critically depend on natural resources, physical capital and low-skill labor but rather on the effective utilization of intangible assets such as knowledge, skills and innovative potential. In this new economic paradigm, there is growing consensus that $\mathrm{PhD}$ holders have a strategic role in the success of firms and nations (European University Association, 2007). PhD recipients represent a key element for innovation and the generation of new knowledge because of their ability to solve complex problems (Stephan et al., 2004). They produce the most up-to-date scientific knowledge (through basic research) and they bring their capabilities to firms, where they help to transform scientific inventions into new market products (Herrera et al., 2010). In addition, employing PhD holders helps firms to cooperate with universities and to create external networks with the scientific community, which often is the only way to access forms of knowledge that are mainly tacit in nature (Garcia-Quevedo et al., 2012).

In recognition of the importance of ensuring an adequate supply of highly educated workers, many countries have expanded and reformed their doctoral programs (Park, 2007). The number of doctoral degrees awarded in OECD countries has increased dramatically in recent 
decades (Auriol, 2010). Moreover, extensive reforms have changed the definition, organization and evaluation of doctoral programs (Kehm, 2007).

Nevertheless, the growing number of $\mathrm{PhD}$ holders has raised concerns about the negative consequences of their possible misallocation in the labor market, especially in view of recent signs of saturation in the academic job market (especially in some European countries). Indeed, the figures obtained for several OECD countries, from the Careers of Doctorate Holders (CDH) survey, highlights that a non-negligible share of $\mathrm{PhD}$ holders end up in jobs unrelated to their $\mathrm{PhD}$ or below their qualification level (Auriol, 2010). Recent reports indicate that jobeducation mismatch is a widespread, persistent problem (Pouliakas, 2013), which generates considerable individual and societal costs. Considering the importance of $\mathrm{PhD}$ holders for the economy, the high cost of doctoral education and the high levels of public funding received by doctoral students, the potential inefficiencies due to job-education mismatches are much higher for $\mathrm{PhD}$ recipients than for other educational groups. Unfortunately, while the literature about mismatch among university graduates is rather extensive, the research for $\mathrm{PhD}$ holders is still in its infancy, mainly due to data restrictions.

Drawing on data for a recent cohort of graduates from public universities in Catalonia (Spain), this paper contributes by adding empirical evidence to the debate on the importance, correlates and consequences of labor market mismatch among PhD holders. In line with the recent literature on university graduates, we consider two different dimensions of mismatch: on the one hand, we rely on information about qualification requirements for the current job, and define $\mathrm{PhD}$ holders as overeducated if their $\mathrm{PhD}$ was not a prerequisite for being recruited. On the other hand, we also exploit information about the skills that are required to perform the current job, and classify individuals as overskilled if they state that the skills they possess are not necessary in the workplace. ${ }^{1}$

Our paper expands current empirical evidence along several lines. First, we discuss the correlates of overskilling and overeducation and show how specific academic features that characterize the development of the $\mathrm{PhD}$ thesis represent indirect conditioning factors. Existing literature mostly focuses on job-related variables and do not inform about potential indirect effects of academic characteristics.

Second, we provide evidence of the different (negative) impacts of overeducation and overskilling on earnings. Furthermore, we show that their detrimental effects are specially pronounced when they are combined. While these results have been showed in the related literature of university graduates, to the best of our knowledge, we provide novel evidence for doctorate holders.

Third, we analyse the effect of overeducation and overskilling on job satisfaction. We confirm that mismatch is harmful for job satisfaction among $\mathrm{PhDs}$ and expand the analysis by considering the effect of both forms of mismatch on satisfaction with different facets of the job. This additional piece of evidence is indeed relevant, since mismatch seems to have a different effect on monetary and non-monetary aspects of the job - an issue that cannot be appreciated by considering overall job satisfaction alone (as done in previous papers).

The rest of this paper is organised as follows. In Section 2 we review the relevant literature. Section 3 presents the data and section 4 illustrates the factors conditioning mismatch among PhD graduates. In Section 5, we explore the consequences of mismatch in terms of earnings (5.1) and job satisfaction (5.2). Finally, Section 6 summarizes the evidence and provides interpretations and policy implications of the results.

\section{Related Research}

The literature on labor market mismatch is quite extensive (Leuven and Oosterbeek, 2011; Pouliakas, 2013). The well-established conclusions emerging from this literature highlight that mismatched workers endure wage penalties, have lower job satisfaction, higher turnover and absenteeism, and lower participation in training. For employers, costs associated with qualification and skills mismatch may take the form of higher recruitment costs, lower productivity and lower product quality. 
Much of the existing research is based on the concept of educational or qualification mismatch, which is defined using educational credentials as a reference point (McGuinness and Bennet, 2007; Carroll and Tani, 2013). More and more authors, however, are using measures of deficits/surpluses in skills or competences (Green and McIntosh, 2007; Mavromaras et al. 2010; McGuinness and Sloane, 2011). The resulting evidence suggests that, quite unexpectedly, educational and skills mismatches are not strongly correlated, indicating that they are distinct empirical phenomena that need to be studied separately. The literature reports negative wage effects stemming from both forms of mismatch with an increasingly robust evidence that the worst situation is to be overskilled and overeducated.

Several papers (Green and Zhu, 2010; McGuinness and Sloane, 2011; Mavromaras et al., 2013) have analysed the impact of qualification and skills mismatch on job satisfaction. Examining the impact of mismatch on job satisfaction along with earnings is especially relevant, because it can reveal whether or not this represents a voluntary status. Workers, for instance, may forego higher wages in favor of other, more satisfying, job attributes, such as job security or work-life balance. Therefore, several authors argued that finding negative effects of mismatch on earnings but positive effects on satisfaction would be suggestive of an intended choice of being mismatched. On the contrary, obtaining negative impacts of mismatch on both satisfaction and earnings indicates that being mismatched is driven by constrains in the labor market. The results of this incipient literature show that, in general, mismatch represents an involuntary situation (i.e. it has a negative effect on both labor market outcomes). Moreover, qualification mismatch per se is not strongly correlated with job satisfaction, whereas underutilisation of acquired skills has more serious consequences, particularly when accompanied by educational mismatch.

Doctoral education has attracted increasing attention in specialized academic journals in recent years, as well as among national and international policy management spheres (European University Association, 2010). However, the evidence on the labour market situation of $\mathrm{PhD}$ holders, while growing, is still quite limited. More importantly, very few papers have focused on the determinants and the effects of job-education mismatch specifically among $\mathrm{PhD}$ holders. Regarding the determinants of mismatch, drawing on data from the US Survey of Doctoral Recipients (SDR), Bender and Heywood (2009) stress the importance of employment sector and work activity as determinant of having a job related to the $\mathrm{PhD}$. In a subsequent paper, Bender and Heywood (2011) exploited the panel structure of the SDR data and found that job changes from the academia to business or government increases the likelihood of mismatch, but mostly at the early stage of the career. On the contrary, the main activity carried out in the workplace affects mismatch also in advanced phases of the working life of $\mathrm{PhD}$ graduates. However, both papers are silent about the potential role of academic attributes, which could indeed act as determinants of mismatch either directly or indirectly (through their effect on job characteristics). More recently, Gaeta (2015) analysed overeducation and overskilling among Italian $\mathrm{PhD}$ graduates, confirming the importance of sector and work activity as conditioning factors of both forms of mismatch. He also included dummies for on time $\mathrm{PhD}$ completion, attending extra courses and pre-doc mobility as controls, and found that the latter two variables negatively correlate with mismatch. We consider that examining the effect of academic characteristic is of special importance, since they capture individual heterogeneity in human capital accumulation that are not fully accounted for $\mathrm{PhD}$ program controls. For this reason, our models contain a large list of academic attributes that could affect mismatch. Moreover, we implement a stepwise inclusion of control variables, which enables analyzing the extent to which academic characteristics affect mismatch indirectly, because of their effect on job-related controls that in turn determine the risk of being mismatched in the labor market.

The evidence about the effect of mismatch among $\mathrm{PhD}$ holders is also limited. Bender and Heywood $(2009,2011)$ estimated the wage penalties due to job-education mismatch among US $\mathrm{PhD}$ holders. They show that having a job that is not related to the $\mathrm{PhD}$ has a negative impact on earnings, which is robust to the inclusion of individual fixed effects. Moreover, in the second paper they also performed separate estimates of the wage penalty associated with mismatch by field of study and at different career stages, and found worse effects for those with a $\mathrm{PhD}$ in 
Hard Sciences and, to a lesser extent, in Social Sciences, as well as for those at an advanced stage of their career.

Canal and Rodríguez (2013) studied wage differences by area of study and employment sector among Spanish PhD holders. Although job mismatch was not their specific focus, they included variables capturing job-PhD relatedness and qualification requirements as controls. The results suggest that working in a job that requires higher education levels (post-doc, $\mathrm{PhD}$, graduate or undergraduate) is associated with higher earnings, relative to occupations that do not require higher education qualifications, especially outside the academic sector.

Regarding job satisfaction, Bender and Heywood (2006) analysed gender differences in job satisfaction among US PhDs across sector (again using SDR data). They also controlled for a proxy of job-PhD relatedness and found that being in occupations closely related to the $\mathrm{PhD}$ improves job satisfaction in all sectors (academy, government and business) and for both males and females. Consistent results have been presented in the analysis of job satisfaction of their subsequent work specifically focused on mismatch among PhDs (Bender and Heywood, 2009). Since their dependent variable refers to overall job satisfaction, they are unable to examine whether or not mismatch has a different effect on satisfaction with different facets of employment, such as monetary and non-monetary elements.

Overall, to the best of our knowledge, this is the first paper providing novel evidence about the impact of overeducation and overskilling on two key labor market outcomes of recent $\mathrm{PhDs}$ : earnings and job satisfaction.

\section{Data and Descriptive Statistics}

Our paper is based on data from a recent cohort of $\mathrm{PhD}$ graduates from public universities in Catalonia, Spain. The number of PhDs awarded by Catalan universities increased from 968 during the 1997-98 academic year to 1,781 in 2010-11 (an increase of 84\%). As can be seen in Figure 1, the increase in doctoral awards in Catalonia has followed the same general tendency observed for Spain as a whole.

\section{[FIGURE 1]}

The rising flow of $\mathrm{PhD}$ holders in recent decades, however, has not caused a major supply shock in the Spanish labor market. In 2011, the doctoral graduation rate was just $1.1 \%$ of the population in the reference age cohort, considerably below the OECD mean of $1.6 \%$ and just slightly up from the rate of 0.9\% reported for Spain in 2011 (OECD, 2013: 94). In 2009 there were 6.7 doctorate holders per thousand population aged 25-64 in Spain, contrasting with 14 in Germany, 13.5 in the United States, and 7.6 in Finland (OECD, 2013:96).

The data used in the empirical analysis in the present study come from a 2011 survey on the early labor market experiences of PhD holders, implemented by the Quality Assurance Agency for the Catalan University System (AQU) ${ }^{2}$. The target population consisted of all Spanish-born individuals who completed a $\mathrm{PhD}$ in one of the seven Catalan public universities in 2006 or 2007. The entire population was composed of 1,824 individuals and 1,225 answered the questionnaire, which corresponds to a fairly high response rate of $67.2 \%$. Graduates were contacted four years after $\mathrm{PhD}$ completion. Therefore, our analysis concerns the short-term mismatch situation of our sample of PhD holders. It could be argued that analyzing this early period in the professional careers of $\mathrm{PhD}$ graduates may be misleading as they are still adjusting to a situation that may evolve towards a better match. While theoretically this would appear to be likely, the scant evidence available suggests that the incidence and the negative effects of mismatch on earnings of US PhDs are more pronounced among those in late careers, but are also present among recent $\mathrm{PhD}$ graduates (Bender and Heywood, 2011), which makes our early career analysis particularly interesting.

The dataset contains basic socio-demographic data, information on academic attributes and the doctoral program followed, as well as detailed information on current employment. We restricted the sample to those individuals who were in a full-time job at the time of the survey and were aged 40 or younger when they started their $\mathrm{PhD}^{3}$. 
The main variables of interest are those concerning the job (mis)match status of $\mathrm{PhD}$ holders, taken from two specific questions from the AQU survey. In the first question, respondents were asked about the educational entry requirements for their current job. Four possibilities were considered: 1) a $\mathrm{PhD}$ degree, 2) a specific undergraduate degree (i.e. the degree held by the individual), c) any undergraduate degree, and d) no qualification requirements. In the second question, respondents were asked whether their $\mathrm{PhD}$-specific skills were necessary in their current job. In this paper we adopt a similar approach than Dolton and Silles (2008). We classify individuals as overeducated if they stated that their $\mathrm{PhD}$ was not necessary for securing their current job and as overskilled if they considered that the skills acquired with the $\mathrm{PhD}$ are not necessary for performing the job. ${ }^{4}$ Table 1 shows the marginal and joint distribution of these two distinct dimensions of mismatch.

\section{[TABLE 1]}

The data indicate that just over $72 \%$ of individuals in our sample were adequately matched in terms of skills and that just $53 \%$ were adequately matched in terms of education. These figures reflect a considerable level of overeducation and overskilling in our cohort of doctors. It is difficult to validate these data due to a lack of comparable information, but they are quite similar to results reported for Spain by Auriol (2010) and Canal and Rodríguez (2013).

Cross-tabulation of education and skills mismatch measures show that the probability of being well matched in terms of skills was significantly higher for $\mathrm{PhD}$ graduates in occupations that required a $\mathrm{PhD}$, meaning that these two distinct facets of (mis)match are likely to be interrelated. Indeed, the correlation between the two mismatch indicators is 0.51 , which is well above the correlation indicated in papers using similar mismatch measures for college graduates. Looking at the extremes, $45 \%$ of our sample can be considered adequately education/skill matched while $26 \%$ were in jobs that did not seem to require neither a $\mathrm{PhD}$ degree nor the skills acquired during doctoral studies (overeducated and overskilled).

What were the characteristics of our graduates? Did mismatch status reflect differences in observed individual, academic and labor market characteristics? ${ }^{5}$ Overall, it appears that mismatch status was clearly related to the academic and professional profile of the individual. Well-matched $\mathrm{PhD}$ holders were more likely to be younger males with a clear academic orientation, as they were more represented among those who developed their $\mathrm{PhD}$ thesis within a research group and completed the doctorate in at most six years. They also tended to have shorter job tenure and were more inclined to work in academia, research institutes or private firms doing R\&D work. The profile of graduates who were both overskilled and overeducated was similar but they had a significantly longer tenure and were more likely to have started working as adjunct professors or research assistants at a university before completing their $\mathrm{PhD}$. It is interesting to note that strongly mismatched graduates were more likely to work either in the government or private sector.

The risk of mismatch also varied markedly across different types of $\mathrm{PhD}$ programs. $\mathrm{PhD}$ graduates in the areas of humanities and social sciences were generally less likely to be wellmatched while the opposite was observed for PhD holders in hard sciences. The evidence for the area of health points out that mismatch was an important problem among $\mathrm{PhD}$ graduates in these fields, especially for those holding a $\mathrm{PhD}$ in Medicine. The incidence of mismatch was moderate among PhDs in technical studies, with the exception of Architecture.

Table A2 in the Appendix also reports descriptive information about potential wage and job satisfaction penalties associated with mismatch status. With respect to raw differences in gross annual earnings, adequately matched doctors were slightly more represented in the modal category (between $€ 30,000$ and $€ 40,000$ ). Interestingly, graduates earning more than $€ 50,000$ (the top-coding category) were significantly more likely to be mismatched, particularly in terms of skills. This is possibly related to the fact that a higher proportion of these graduates worked in the better-paid private sector. The survey also provided information about perceived satisfaction. On average, job satisfaction was rather high (5.7 on a 1-7 scale) and the respondents were especially satisfied with promotion opportunities, but less happy with job content and pay. As expected, 
those who were overeducated and even more so those who were overskilled were significantly less satisfied with the match between their skills and the work they were doing.

\section{The correlates of qualification and skills mismatch}

In this section we examine the variables conditioning mismatch. We estimated two Seemingly Unrelated Bivariate Probit equations that model the probability of being overskilled and of being overeducated. This allowed us to check for significant differences in the conditional association between the explanatory variables and each of the two types of mismatch. Table 2 shows the average changes in the predicted probabilities for four different specifications of the two equations. The baseline specification (1) contains socio-demographic variables, academic credentials and indicators for pre-and post-doctoral mobility. Model (2) adds the type and region of work, model (3) job attributes, and model (4) information on the main activities performed at work ${ }^{6}$. This stepwise inclusion of controls was designed to observe whether and how academic and job-related attributes separately affect the likelihood of being overeducated and/or overskilled. Additionally, each model contains fixed PhD-type and university effects to capture factors shared by graduates with similar PhDs across the seven universities. As expected, the estimated correlation between the residuals of the two equations was positive and significant in all cases, pointing to the presence of common unobserved determinants of overskilling and overeducation.

\section{[TABLE 2]}

Two immediate points emerge from the results of our analysis. First, the effect of academic attributes seems to be mainly indirect, since it loses importance once we control for the full set of work characteristics. Second, the stepwise inclusion of different groups of regressors did not generate striking changes in the estimated coefficients as we moved from one model to the next in terms of direction and statistical significance, meaning that the general picture of the conditioning factors of mismatch among $\mathrm{PhD}$ holders in our series remained largely unchanged.

Female graduates were more likely (around 5 percentage points [p.p] higher) to be overskilled than male graduates with similar characteristics, but we did not observe any gender differences in terms of overeducation. This finding could be a cause for concern as it might mean that while the formal process of accessing the labour market is similar for men and women, there may be subsequent (discriminatory) filtering of women into jobs or tasks requiring fewer skills. Age appeared to be unrelated with overskilling, whereas it had a negative effect on overeducation only when job characteristics were controlled for (probably reflecting cohort effects in education requirements).

Academic experience variables were divided into three groups: source of $\mathrm{PhD}$ funding, academic attributes that characterise $\mathrm{PhD}$ studies and research mobility. Ideally, these variables would capture the quality of training received and, therefore, signal the best doctoral graduates, who, in a normal, well-functioning labour market, should be better matched ${ }^{7}$. However, if $\mathrm{PhD}$ programs are, at least to some extent, designed to attract and channel students into the academic profession, these variables could also be capturing a sorting process into specific labour markets. The coefficients estimated show that the academic experience has a modest impact on the probability of being overskilled, but are markedly relevant for explaining the probability of being overeducated.

Funding one's $\mathrm{PhD}$ through any of the three main mechanisms analysed did not seem to be associated with dramatic differences in mismatch status. It should be noted, however, that scholarships were generally associated with a lower incidence of both overeducation and overskilling, but this beneficial effect tended to be lost once job characteristics were controlled for. This means, at least to some extent, that individual profiles simply affect occupational choices, which, in turn, determine the chances of being mismatched or not. For the small group of students working in jobs unrelated to their PhDs during their doctoral studies (about $4 \%$ of the sample), we observed a higher risk of being affected by both forms of mismatch. These students might represent the least able students (those unable to secure a more favorable way of 
funding their $\mathrm{PhD}$ ), but it is also possible that their desire to obtain a $\mathrm{PhD}$ was driven more by a 'consumption' motivation than by academic/professional goals.

The results for academic attributes capturing individual performance indicate that $\mathrm{PhD}$ duration had no impact on the probability of being mismatched. However, working in a research group while pursuing one's $\mathrm{PhD}$ favoured access to jobs requiring a $\mathrm{PhD}$ degree, but its positive effect on the likelihood of the acquired skills' being fully utilised disappeared after controlling for employment sector. This observation clearly points to the value of using research infrastructures as a stepping stone towards an academic career requiring a $\mathrm{PhD}$.

Pre-doctoral research mobility and, most notably, post-doctoral mobility in national or international institutions decrease the probability of being mismatched by about 25 p.p. (relative to no post-doctoral mobility). Mobility experiences allow acquiring productive skills and personal maturity that most likely are rather difficult to reproduce in the student's own institution during the regular training period. Moreover, research mobility, particularly following completion of a $\mathrm{PhD}$, might also have a positive impact on job quality resulting from increased networking opportunities. This is indeed confirmed by the fact that although the size of the effect of research mobility diminishes after controlling for job-related variables, still remains important (especially for overskilling).

Moving to the results obtained in the models where job-related variables are included as additional covariates, we must stress that the employment sector was of fundamental importance for explaining the likelihood of being overeducated and, in particular, of being overskilled. Working in the private sector and even more so in the public sector (i.e. government, public administration and other public non-academic institutions) substantially increased the chances of being mismatched and, even though this penalty was reduced after controlling for the main activities at work, it remained sizeable and significant. On the contrary, those who worked in research institutes were not more likely to be overskilled and were just slightly more likely to be overeducated when job attributes and main activities were maintained constant. These results are remarkable, especially considering that working outside an academic-research environment has a very large impact on the probability of being overskilled. They suggest that the problem of mismatch among $\mathrm{PhD}$ holders is not just related to a lack of recognition of the $\mathrm{PhD}$ credential outside the university (i.e. overeducation), but also point to a more fundamental problem related to a clear underutilisation of skills by many employers.

The estimates of work location suggest that working outside Spain was associated with a lower probability of being mismatched. This could reflect either positive sorting of $\mathrm{PhD}$ holders who migrated after completing their $\mathrm{PhD}$ or a higher supply of suitable jobs in destinations to which Spanish $\mathrm{PhD}$ graduates were likely to migrate, namely Northern Europe and the US. The estimated marginal effects for the additional job-related controls highlighted a sizeable positive effect of job tenure on overeducation. This result might be explained by the cohort nature of our data and also perhaps by the fact that some graduates in our sample may have started their current job before completing their PhD. However, seniority seemed to be unrelated to the likelihood of overskilling. In our sample, those with a permanent contract were slightly more likely to be adequately matched in terms of qualifications than others. In agreement with evidence reported for college graduates, we found that working in a medium-large firm (250500 workers) had a beneficial effect on the probability of being adequately matched.

Finally, model (d) controlled for the main activities at work for those employed in nonuniversity settings. Therefore, the effect of these variables in this model has to be interpreted as the impact of job task variation once the 'average' effect of employment sector has been controlled for. As expected, working in R\&D reduced the likelihood of being mismatched in a consistent way for both indicators. This means that working outside a university per se was not synonymous with mismatch. Rather, the higher risk of being mismatched depended on whether or not $\mathrm{PhD}$ skills were utilised in (non-academic) jobs. In other words, working outside academia, but in a research-related job, would compensate for the higher average likelihood of mismatch among private and public sector workers. This was also confirmed by the positive conditional relationship of performing technical support tasks on both forms of mismatch, as well as the increased likelihood of those working in management and health care being 
mismatched. However, this last point should not be interpreted in terms of having 'too many skills' but rather in terms of having skills that are not useful for a particular job.

Overall, our results confirm the crucial importance of key job characteristics such as employment sector and job-tasks as conditioning factors of mismatch among $\mathrm{PhD}$ recipients, as highlighted by Bender and Heywood $(2009,2011)$ and Gaeta (2015). However, we have underscored the impact of academic variables on the probability of suffering some form of mismatch. These variables appeared to operate indirectly (although not exclusively so), since their effect on mismatch was mediated by job-characteristics. That is, academic attributes affected the kind of job $\mathrm{PhD}$ holders obtained after completing their studies, which in turn determined the chances of being or not being mismatched in the labour market.

\section{Were mismatched doctors penalised?}

\subsection{Mismatch and earnings}

In this section we examine the potential labor market penalty associated with job mismatch in our cohort of recent doctors. We estimated an extended earnings equation that includes several academic attributes and job characteristics as control variables, following an 'assignment' view of the labour market in which both individual human capital and academic and job characteristics determine earnings.

Table 3 shows the estimates from the augmented earnings regression ${ }^{8}$. Following Mavromaras et al. (2013), we included the four job match statuses in our model: adequately matched, overskilled, overeducated, and overskilled and overeducated. Our results indicate that being overskilled or overeducated was not statistically associated with earnings, suggesting that $\mathrm{PhD}$ recipients in these two categories did not earn less than their adequately matched counterparts. On the contrary, compared to well-matched graduates, those who were both overeducated and overskilled faced a wage penalty of about $12 \%$. These results are similar to those obtained for college graduates. Even though we used a different measure of mismatch, our results are also consistent with findings obtained by Bender and Heywood $(2009,2011)$ for US $\mathrm{PhD}$ holders, as well as with the evidence for Spain reported by Canal and Rodríguez (2013). Also using panel data, Frenette (2004) did not detect a substantial wage penalty among overeducated Canadian PhD holders. This might be taken as further evidence that, unless accompanied by a certain degree of skills mismatch, overeducation does not have a detrimental effect on job match among PhD graduates.

\section{[TABLE 3]}

The estimates of the control variables in our model are quite standard and are just briefly discussed. The results show a significant ceteris paribus gender difference in annual earnings in favor of male doctors. As expected, earnings rose with age at job entry and job tenure and graduates who obtained their $\mathrm{PhD}$ while working in a job related to their studies earned more, reflecting human capital accumulation through experience. However, a longer time between finishing college and starting one's $\mathrm{PhD}$ studies had a negative effect. Moreover, graduates who took more than 6 years to finish their $\mathrm{PhD}$ studies endured a wage penalty.

There was a sizable positive earnings differential in favor of $\mathrm{PhD}$ holders working in the private sector compared to the university sector, but no significant differences were detected among those working in research institutes or in the public sector. The public sector dummy coefficient is however significantly higher and statistically different from zero when main activities at work are excluded from the model ${ }^{9}$, suggesting that $\mathrm{PhD}$ recipients who worked in the public sector earned more than those who worked in a university only if they performed certain activities that were better remunerated, such as management and health care work.

As expected, we also found positive earnings returns to having a permanent contract and working in medium-large firms. Moreover, $\mathrm{PhD}$ recipients who performed management and health-related tasks were better paid than others. The estimates from the PhD-type fixed effects revealed that those with a $\mathrm{PhD}$ in Biology earn more than those who studied Humanities, 
Sociology, Political Science or Communication, but less than those who studied Economics, Business, Chemistry, Medicine, or Computer and Information Engineering.

\subsection{Mismatch and job satisfaction}

In this section we analyse the conditional association between job mismatch and job satisfaction. We consider perceived overall job satisfaction as an aggregate indicator of all relevant aspects of the job. Moreover, we also analyse perceived satisfaction with four distinct facets of the job, namely promotion opportunities, earnings, job content and job-skills match. Running separate regressions for overall satisfaction and job-domains satisfaction would provide a better insight into the channel through which mismatch affects the level of utility derived from the job. Given the ordinal nature of the variables in question, we applied the standard Ordered Probit approach.

Table 4 shows the marginal effect of each mismatch indicator on the probability of being very satisfied (the highest category) with the job as a whole and with each job domain ${ }^{10}$. It appears that mismatched $\mathrm{PhD}$ holders are not less satisfied with earnings and career prospects than their well-matched peers. However, being mismatched is significantly associated with a lower probability of being very satisfied with job content and job-skills match, two domains that reflect intrinsic and non-monetary aspects of the job. Specifically, graduates in the overeducated category are less satisfied with job content and jobs-skills match, although educational requirements per se appear to have a lower impact on job satisfaction than skills utilisation. Indeed, skills underutilisation makes $\mathrm{PhD}$ holders significantly less likely to be very satisfied with job content and job-skills match. Moreover, the satisfaction loss for being both overeducated and overskilled is very similar to that associated with being overskilled only, indicating that underutilisation of skills is significantly more damaging to job satisfaction than disregard of the attained qualification.

\section{[TABLE 4]}

A more general view of the relationship between job mismatch and job satisfaction among $\mathrm{PhD}$ holders can be obtained from the estimates of the overall satisfaction equation. Overall job satisfaction represents an aggregate of job domain satisfaction and very probably includes additional domains to the four we considered (van Praag and Ferrer-i-Carbonell, 2007). Consistent with the results for job content and job-skill match satisfaction, being overeducatedhas only a modest negative effect on satisfaction with the job as a whole (which is imprecisely estimated). By contrast, job satisfaction is significantly lower when overeducation and overskilling are combined and is lower still among $\mathrm{PhD}$ graduates who are overskilled but not overeducated (although this estimate is less precise because of the few observations in this category). It might be that overeducated doctors enjoy other features of their job that would compensate for underutilisation of skills (compensating differentials). Alternatively, it is possible that the requirement of a $\mathrm{PhD}$ to get the job might have falsely raised the graduate's expectations regarding the need for his/her skills. Whatever the case, our results are in line with those of Bender and Heywood $(2006,2009)$, indicating that mismatch reduces job satisfaction. Our analysis of job-domains satisfaction reveals that most of the effect of mismatch is due to the lack of suitable non-monetary job characteristics, rather than monetary aspects. In conclusion, it is possible to claim that overskilling is unlikely to be voluntary.

\section{Conclusions}

Analysing job mismatch among Spanish PhD holders, we drew on data from a recent cohort of $\mathrm{PhD}$ graduates from the public university of Catalonia (Spain). Following the recent literature on job mismatch among highly educated workers, we have distinguished between two forms of mismatch: education mismatch and skills mismatch. Overall, our analysis reveals a worrisome situation in which a non-negligible proportion of recent $\mathrm{PhD}$ graduates face involuntary 
mismatch associated with a significant penalty in terms of job satisfaction and, in the most severe case, earnings.

Our results show that these phenomena of overeducation and overskilling are quite closely correlated. This indicates that employers' recruitment and promotion strategies are quite closely aligned with actual job content, reflecting a clear understanding of what can be accomplished by a $\mathrm{PhD}$ graduate. The $\mathrm{PhD}$ job market is segmented into, on the one hand, jobs at universities and research institutes where graduates' credentials and skills are recognised and largely used, and, on the other hand, jobs in the public and private sectors where this is not so much the case. The main conditional correlates of job mismatch are sector of employment and the activities performed within the sector, which are in turn affected by $\mathrm{PhD}$ holders' academic attributes. It is important to stress that the problem of mismatch is more closely related to the skills requirements of the job rather than to employment in a private firm or the public sector. In other words, job mismatch, especially in terms of overskilling, seems to be more sensitive to the demand side than the supply side of the labor market.

We also investigated the impact of mismatch on earnings and job satisfaction. As in the case of college graduates, $\mathrm{PhD}$ holders face a severe wage penalty only when they are both overeducated and overskilled. They show a high level of job dissatisfaction mostly related to non-monetary elements (reflecting intrinsic job quality). Those who are either overeducated or overskilled are, at least partly, compensated by higher earnings, but this does not offset the lack of relevant non-monetary aspects of the job that are highly valuable for $\mathrm{PhD}$ holders. Our results show that it is the extent to which new doctors can exploit their 'scientific' knowledge (i.e. their research potential) in the workplace what determines job satisfaction.

The sector of employment plays an important role in determining earnings. A private sector job commands a sizeable wage premium, casting doubts on the claim that $\mathrm{PhD}$ holders do not have skills required to be productive outside the academic world. It seems, however, that a certain number of graduates working in private companies (and to some extent in government and other public sector jobs) undertake tasks that are more closely related to management than to R\&D. Despite their higher earnings, these graduates feel that their skills are being misused which is reflected in the job satisfaction analysis. This apparent contradiction could be explained by the fact that PhDs' 'high taste for science' is not fulfilled in their jobs (Stern, 2004; Roach and Sauermann, 2010; Agarwal and Ohyama, 2013).

We consider that our results can be interpreted within the broader discussion of the availability of adequate jobs for the increasing number of $\mathrm{PhD}$ holders entering the labor market. The growing influx of graduates may have not been adequately absorbed by a labor market that, on the one hand, is creating fewer academic and research jobs and, on the other, has long been incapable of effectively channelling new graduates into suitable jobs in industry, private business, or in the public sector. This does not mean, however, that new $\mathrm{PhD}$ graduates lack the skills to be successful in positions with a clear research and innovation content outside the academic world. In addition, there are signs that these graduates, when placed in middleand top-management positions, can be a key asset. Unfortunately, there seems to be a misalignment between the skills acquired during the completion of a $\mathrm{PhD}$ and those required in management positions.

The results presented in this paper call for a new set of policies aimed at reforming supply and demand conditions. From the demand perspective, it is clear that Spanish firms must continue to transform their structures and incorporate more $R \& D$ activities to increase their competitiveness. However, in addition to fostering such changes, more attention should be given to promoting collaboration between the business world and universities, through initiatives such as joint research projects, research spin-offs and co-training of graduates. From the supply perspective, there is a need for policies aimed at developing what has been called a 'new skills agenda', with horizontal and transferable skills, such as managerial, organisational, leadership and teamwork skills that are transferable to a range of career paths, within and beyond research (Mangematin, 2000; Lee et al., 2010). 


\section{Acknowledgements}

This article was developed from an earlier working paper that circulated under the name "Are we wasting our talent? Overqualification and overskilling among $\mathrm{PhD}$ graduates" and benefited from the comments and suggestions received from expert researchers in the field. Specifically, the authors would like to thank Maite Blázquez, Samuel Bentolila, Santi Budría, Ada Ferrer-iCarbonell, Xavi Ramos, Massimiliano Tani and Yu Zhu, the two anonymous referees and the editor for useful suggestions. Thanks are also due to participants at the XXI AEDE conference, the XVII AIEL conference, the XXXVII SAE conference, the II Lisbon workshop on Economics, Statistics and Econometrics of Education, the III SEEK conference and the IV IWAEE workshop.

\section{Funding}

This work was supported by the Spanish Ministry of Education [ECO2013-41022-R; ECO201342884-P]

\section{Author biographies}

Antonio Di Paolo is assistant professor in the Department of Econometrics of the University of Barcelona and has been a visiting researcher at the Institute for Social and Economic Research, the German Institute for Economic Research (DIW Berlin) and the Centre for European Economic Research (ZEW, Mannheim). His research interests are education and labour economics with special focus on intergenerational mobility in education, language knowledge and returns to language skills, as well as job-education mismatch.

Ferran Mane is an Associate Professor at the Economics Department, Universitat Rovira i Virgili and director of the Employment Observatory, Universitat Rovira i Virgili. He has been a visiting professor at Essex, Cornell, and University of California Davis. He has also worked as a consultant and research director in projects for the European Union, Cedefop, the International Labor Office, and numerous consulting firms. His research interests are education and labor economics, with special focus on the supply and demand of education and skills.

\section{References}

Agarwal R. and Ohyama A (2013) Industry or academia, basic or applied career choices and earnings trajectories of scientists. Management Science 59(4): 950-970.

Auriol L (2010) Careers of Doctorate Holders: Employment and Mobility Patterns. OECD Science, Technology and Industry Working Papers 2010/4. Paris: OECD Publishing.

Bender KA and Heywood JS (2006) Job satisfaction of the highly educated: The role of gender, academic tenure, and earnings. Scottish Journal of Political Economy 53(2): 253-279.

Bender KA and Heywood JS (2009) Educational mismatch among Ph.D.s: Determinants and consequences. In Freeman RB and Goroff DL (eds) Science and Engineering Careers in the United States: An Analysis of Markets and Employment. Cambridge MA: National Bureau of Economic Research, Inc., pp. 229 - 255 
Bender KA and Heywood JS (2011) Educational mismatch and the careers of scientists. Education Economics 19(3): 253-274.

Canal Domínguez JF and Rodríguez Gutiérrez C (2013) Wage differences among Ph. Ds by area of knowledge: are science areas better paid than humanities and social ones? The Spanish case. Journal of Education and Work 26(2): 187-218.

Carroll D and Tani M (2013) Over-education of recent higher education graduates: New Australian panel evidence. Economics of Education Review 32(C): 207-218.

Cedefop (European Centre for the Development of Vocational Training) (2010) The skill matching challenge: analysing skill mismatch and policy implications. Luxembourg. Publications Office. Available: http://www.cedefop.europa.eu/EN/Files/3056_en.pdf (accessed 1 June 2016).

Dolton PJ and Silles MA (2008) The effects of over-education on earnings in the graduate labour market. Economics of Education Review 27(2): 125-139.

EUA (European University Association) (2007) Doctoral programmes in Europe's universities: achievements and challenges: Report prepared for European universities and ministers of higher education. Brussels and Geneva: EUA.

EUA (European University Association) (2010) EUA policy document on quality and quality assurance in the European Higher Education Area. Brussels and Geneva: EUA.

Gaeta GL (2015) Was it worth it? An empirical analysis of over-education among $\mathrm{PhD}$ recipients in Italy. International Journal of Social Economics 42(3): 222-238.

García-Quevedo J, Mas-Verdu, F and Polo JL (2012) Which firms want PhDs? An analysis of the determinants of the demand. Higher Education, 63(5): 607-620.

Green, F. and McIntosh, S. (2007) Is there a genuine under-utilization of skills among the overqualified? Applied Economics 39(4): 427-439.

Green F and Zhu Y (2010) Overqualification, job dissatisfaction, and increasing dispersion in the returns to graduate education. Oxford Economic Papers 62(4): 740-763.

Herrera L, Muñoz-Doyague MF and Nieto M (2010) Mobility of public researchers, scientific knowledge transfer, and the firm's innovation process. Journal of Business Research 63(5): 510-518.

Lee HF, Miozzo M and Laredo P (2010) Career patterns and competences of PhDs in science and engineering in the knowledge economy: The case of graduates from a UK researchbased university. Research Policy 39(7): 869-881.

Kehm BM (2007) Quo vadis doctoral education? New European approaches in the context of global changes. European Journal of Education 42(3): 307-319.

Leuven E and Oosterbeek H (2011) Overeducation and mismatch in the labor market. In Hanushek EA, S.Machin S. and Woessmann,L (eds) Handbook of the Economics of Education.Amsterdam: Elsevier, pp. 283-326.

Mangematin V (2000) PhD job market: Professional trajectories and incentives during the PhD. Research Policy 29(6):741-756.

Mavromaras KG, McGuinness S, O'Leary NC, Sloane PJ and Fok YK (2010) The problem of overskilling in Australia and Britain. The Manchester School: 78(3): 219-241.

Mavromaras KG, McGuinness S, O'Leary NC, Sloane PJ and Wei Z (2013) Job mismatches and labour market outcomes: Panel evidence on Australian University graduates. Economic Record 89(286): 382-395.

McGuinness S and Bennett J (2007) Overeducation in the graduate labour market: A quantile regression approach. Economics of Education Review 26(5): 521-531.

McGuinness S and Sloane PJ (2011) Labour market mismatch among UK graduates: An analysis using REFLEX data. Economics of Education Review 30 (1): 130-145.

OECD (Organsiation for Economic Cooperation and Development) (2013) Science, Technology and Industry Scoreboard 2013. Paris: OECD.

Park C (2007) Redefining the Doctorate. York: Higher Education Academy.

Pouliakas K (2012) The Skill Mismatch Challenge in Europe. Employment and Social Developments in Europe 2012. Luxembourg: Publications Office of the European Union. 
Roach M and Sauermann H (2010) A taste for science? Ph.D. scientists' academic orientation and self-selection into research career in industry. Research Policy 39(3): 422-434.

Stephan P, Sumell A, Black G and Adams J (2004) Doctoral education and economic development: The flow of new PhDs to industry. Economic Development Quarterly 18(2): 151-67.

Stern S (2004) Do scientists pay to be scientists? Management Science 50(6): 835-853. van Praag BMS and Ferrer-i-Carbonell A (2007) Happiness Quantified: A Satisfaction Calculus Approach. Oxford: Oxford University Press.

\footnotetext{
${ }^{1}$ Cedefop (The European Centre for the Development of Vocational Training) (2010) provides clear-cut definitions and discusses the differences between overeducation and overskilling. McGuinness and Sloane (2011: 131) argue that 'overeducation relies on comparing a proxy measure of individual skills (educational attainment) with a proxy measure of the skill content of the job (job entry requirements). However, overskilling allows for a more direct comparison of the individual's accumulated skills, whether they relate to formal education, on-the-job training or perceived innate ability, with the actual skill requirement of the job in question. Indeed, the literature to date suggests that there is a less than a perfect correlation between overeducation and overskilling and that both phenomena tend to have quite distinct implications for workers'.

${ }^{2}$ See http://www.aqu.cat/insercio/index.html\#.Uqs8htGA3mR for details of the survey.

${ }^{3}$ Only $3 \%$ of the sample was not working at the time of the survey. However, we estimated models controlling for the self-selection into employment and it didn't change any result.

${ }^{4}$ This classification also resembles the one used by Mavromaras et al. (2013), except for the fact that they considered a statistical definition of overeducation (based on modal schooling within occupations).

${ }^{5}$ Table A1 in the Appendix deploys a complete description of explanatory variables used in this paper selected using existing empirical works (e.g. Mangematin, 2000; Bender and Heywood, 2009 and 2011 and Canal and Rodriguez, 2013).

${ }^{6}$ The various categories were not mutually exclusive in the sense that individuals might perform more than one activity. Moreover, this information is reported only for individuals who worked outside the university.

${ }^{7}$ We cannot rule out the presence of self-selection of the best students into specific situations. Nevertheless, fixed effects for $\mathrm{PhD}$ program and university should capture part of the training quality dimension.

${ }^{8}$ Notice we retained only those academic attributes that were directly related to human capital accumulation.

Moreover, we included age at job entry rather than current age to better proxy for previous labor market experience.

${ }^{9}$ These additional results are not shown, but are available upon request.

${ }^{10}$ Complete results were quite standard and are not discussed for brevity reasons (but are reported in table A3 in the Appendix). Notice that we also included earnings categories dummies as additional regressors in satisfaction equations.
} 